\title{
Education level as a prognostic indicator at 12 months following decompression surgery for symptomatic lumbar spinal stenosis
}

\author{
Galal A. Elsayed, MD, ${ }^{1}$ Esther B. Dupépé, MD, MSPH, ${ }^{1}$ Matthew S. Erwood, MD, ${ }^{1}$ \\ Matthew C. Davis, MD, MPH, ${ }^{1}$ Samuel G. McClugage III, MD, ${ }^{1}$ Paul Szerlip, PhD, ${ }^{2}$ \\ Beverly C. Walters, MD, MSc, FRCSC, ${ }^{1}$ and Mark N. Hadley, MD ${ }^{1}$ \\ ${ }^{1}$ Department of Neurosurgery, University of Alabama at Birmingham, Alabama; and ${ }^{2}$ Department of Computer Science,
University of Central Florida, Orlando, Florida
}

\begin{abstract}
OBJECTIVE The goal of this study was to analyze the effect of patient education level on functional outcomes following decompression surgery for symptomatic lumbar spinal stenosis.

METHODS Patients with surgically decompressed symptomatic lumbar stenosis were collected in a prospective observational registry at a single institution between 2012 and 2014. Patient education level was compared to surgical outcomes to elucidate any relationships. Outcomes were defined using the Oswestry Disability Index score, back and leg pain visual analog scale (VAS) score, and the EuroQol-5 Dimensions questionnaire score.

RESULTS Of 101 patients with symptomatic lumbar spinal stenosis, 27 had no college education and 74 had a college education (i.e., 2-year, 4-year, or postgraduate degree). Preoperatively, patients with no college education had statistically significantly greater back and leg pain VAS scores when compared to patients with a college education. However, there was no statistically significant difference in quality of life or disability between those with no college education and those with a college education. Postoperatively, patients in both cohorts improved in all 4 patient-reported outcomes at 3 and 12 months after treatment for symptomatic lumbar spinal stenosis.
\end{abstract}

CONCLUSIONS Despite their education level, both cohorts showed improvement in their functional outcomes at 3 and 12 months after decompression surgery for symptomatic lumbar spinal stenosis.

https://thejns.org/doi/abs/10.3171/2018.6.SPINE18226

KEYWORDS education; neurosurgery; lumbar stenosis; outcome assessment; adult

$\mathrm{P}$ ATIENT-REPORTED outcomes are commonly used to evaluate the benefit offered by medical or surgical treatments. ${ }^{4,5,22}$ In this way, they help define preoperative strategy, shape patient expectations, and guide quality improvement for surgeons, third-party payers, and policymakers. ${ }^{1,5,16}$ Although numerous factors may have a role in patient-reported outcomes, one potential characteristic of interest is patient education level.

Several authors have reported that patients with less education (i.e., high school education or less) experience increased pain. ${ }^{9,10,12,13,18,23,28}$ The Spine Patient Outcomes Research Trial (SPORT) provided multiple subgroup anal- yses illustrating this topic in patients with intervertebral disc herniations (IDHs). In the SPORT, patients with lower education levels had worse postoperative outcomes in the surgically treated IDH cohort and showed less improvement with nonoperative therapy than their counterparts with a college education. . $^{8,16,18,24}$ However, there was no difference in improvement for disability, pain, or physical function scores at 4 years postoperatively for IDH, regardless of patients' educational background. ${ }^{16,18}$

In contrast, there is no consensus on the association between patient education level and patient-reported outcomes in symptomatic lumbar stenosis. ${ }^{13-15}$ The SPORT

ABBREVIATIONS EQ-5D = EuroQol-5 Dimensions; GED = General Equivalency Development; IDH = intervertebral disc herniation; $M C I D=$ minimum clinically important difference; ODI = Oswestry Disability Index; SPORT = Spine Patient Outcomes Research Trial; VAS = visual analog scale.

SUBMITTED February 23, 2018. ACCEPTED June 4, 2018.

INCLUDE WHEN CITING Published online October 5, 2018; DOI: 10.3171/2018.6.SPINE18226. 
subgroup analyses failed to report a particular link between outcomes and patient education in this group. Instead, overall improvement was seen for all surgically treated patients regardless of patient factors, with the only exception being worse outcomes in the smoking subgroup. ${ }^{21}$ Meanwhile, a study by Kim et al. from 2014 did show an inverse association between pain and patient education level in a South Korean population. ${ }^{13}$ To our knowledge, this publication by Kim et al. is the first to focus on the topic in patients with symptomatic lumbar stenosis, and a similar examination has never been done within the United States.

The present study is an attempt to further define the relationship, if any, that education level has on patientreported outcomes following decompressive surgery for symptomatic lumbar spinal stenosis.

\section{Methods \\ Data Collection}

Data were collected in a prospective observational registry based on previously published methods for collection, abstraction, and implementation., ${ }^{2,3,17}$ Data were entered by coordinators and abstractors at the University of Alabama at Birmingham through a secure portal (REDCap [Research Electronic Data Capture]). De-identified data were exported from the secure portal for all patients with lumbar spinal stenosis who were enrolled in the registry between February 2012 and June 2014. In addition to patient demographics, morbidity, and mortality, the patientreported metrics at baseline and 3 months and 12 months postintervention were recorded.

Data entry for our institutional quality and outcomes database considers for enrollment all patients with lumbar spine surgery who undergo surgery at the department of neurosurgery. Initial exclusion criteria include all spinal infections, spinal tumors, traumatic fractures, patient incarceration, age less than 18 years, refused consent, nonlumbar location, and nonparticipating surgeon. From here, further lumbar-specific exclusion criteria are considered, consisting of deformity, spondylolisthesis grades II-IV (Meyerding classification), ossification of the posterior longitudinal ligament, sacroiliac joint fusions, chronic regional pain syndrome, cognitive/psychiatric impairment, severe peripheral neuropathy, and neurological paralysis. Key inclusion criteria are disc herniation, degenerative disease, lumbar stenosis, grade I spondylolisthesis, disc collapse, and adjacent-segment disease.

All patients who are ultimately enrolled must meet administrative criteria of sufficient follow-up and medical record documentation. The enrollments are carried out on a 6-day accrual cycle, with no more than 6 patients enrolled over a weeklong time frame. Enrollments are also sequential in nature, in that the signup closes after the first 6 eligible patients are enrolled and an entirely new set of patients is considered the following week.

The collection and analysis of these data qualified for exemption from the University of Alabama at Birmingham Institutional Review Board process due to a previously approved methodology of data collection and patient-reported outcomes research associated with this prospective observational registry.

\section{Study Design}

An observational cohort study design was used to assess the role of education level on patient-reported outcomes after decompression surgery for symptomatic lumbar spinal stenosis. Patients were stratified into 2 cohorts based on education level: less than high school, high school diploma, or certificate of General Equivalency Development (GED) versus a 2- or 4-year college degree or postgraduate education. The study design adhered to the Strengthening the Reporting of Observational Studies in Epidemiology (STROBE) guidelines. ${ }^{26}$

\section{Study Measures}

The 4 patient-reported measures used for this study included back and leg pain based on visual analog scale (VAS) scores, the Oswestry Disability Index (ODI), and the EuroQol-5 Dimensions (EQ-5D) questionnaire. These were measured at baseline, 3 months postintervention, and 12 months postintervention.

\section{Statistical Analysis}

Descriptive and univariate analyses involved a test for normality, and parametric data were presented as the mean \pm standard deviation (SD) and compared using the Student t-test. Related parametric data sets were given as the mean \pm SD calculated using a paired t-test. Fisher's exact test was used for comparing nominal data. A p value $<0.05$ was used for statistical significance. All univariate analyses were performed using IBM SPSS software (version 23.0, IBM Corp.).

In addition to a univariate analysis, a multivariate analysis was performed to determine the role of previously published covariates. ${ }^{27}$ Multiple regression models using both continuous dependent variables and categorical independent variables were performed for baseline, 12 months postintervention, and the difference in magnitude between baseline and 12 months postintervention among the patient-reported outcomes for these time points. Sex, smoking status, diabetes, and reported depression were included as covariates. RStudio (version 0.99.902) and R programming language (version 3.2.3) were used to perform multiple regression analyses.

\section{Results \\ Baseline Patient Characteristics}

A total of 101 patients were included in this prospective observational cohort study. Twenty-seven patients had an education below the college level, whereas 74 patients reported a college education (Table 1). For the cohort with a high school education or below, 26 of the 27 patients experienced more than 3 months of symptoms prior to operative intervention. In the cohort with a college education, 66 of the 74 patients had more than 3 months of symptoms. Differences in age, insurance status, presence of anxiety, body mass index, depression diagnosis, ambulation status, sex, American Society of Anesthesiologists class, and smoking status were not significant between the 2 patient cohorts (Table 2). Although a minority of patients responded to the question about occupation, descriptions 
TABLE 1. Level of education distribution among patient population

\begin{tabular}{lcc}
\hline \multicolumn{1}{c}{ Level of Education } & $\begin{array}{c}\text { Less-Educated } \\
\text { Group, } \mathrm{n}=27\end{array}$ & $\begin{array}{c}\text { More-Educated } \\
\text { Group, } \mathrm{n}=74\end{array}$ \\
\hline Less than high school & $3(11.11 \%)$ & \\
\hline High school diploma or GED & $24(88.89 \%)$ & \\
\hline 2-yr college degree & & $17(22.97 \%)$ \\
\hline 4-yr college degree & $29(39.19 \%)$ \\
\hline Postgraduate & $28(37.84 \%)$ \\
\hline
\end{tabular}

of their job activity levels are included as well. Three patients with an education level of high school or below underwent fusion, and 6 fusions occurred in the college-educated cohort. Typically, indications for fusion involve the identification of instability on preoperative examination and/or radiographs, or if the requirements for decompression of the neural elements necessitate making the patient mechanically unstable.

\section{Results of Patient-Reported Outcomes}

Back and leg pain scores as measured using the VAS showed a statistically significant difference between the more- and less-educated cohorts at baseline testing. As indicated in Table 3, those with no college education had greater back and leg pain than their counterparts with a college education. However, this statistical significance seen at baseline did not carry over into testing at 3 and 12 months after lumbar decompression. A similar trend was seen in the results of EQ-5D, with statistically significantly higher scores in the college education cohort at baseline, but no statistical significance thereafter. The ODI results, meanwhile, were not significant at any time point. In fact, score averages across VAS arm and leg, EQ$5 \mathrm{D}$, and ODI were generally worse in the less-educated population, although many did not approach significance (Table 3, Fig. 1).

As a next step, the 78 patients with complete data across VAS, EQ-5D, and ODI were used for paired testing comparing the following: baseline to 3 months, baseline to 12 months, and 3 months postintervention to 12 months postintervention (Table 4, Fig. 1). This paired testing revealed that among those patients with no college education $(n=23)$, there was a statistically significant improvement in back and leg pain between their baseline and 3-month VAS scores. Similar improvement was seen between baseline and 12-month findings. However, VAS scores revealed a regression of postoperative gains in the less-educated cohort that was of statistical significance, at a value of -1.80 for back pain and -1.71 for leg pain. In the college-educated group, improvements were again seen in the baseline to 3-month and baseline to 12-month comparisons, but regression was either not seen or was not statistically significant between the 3-month and 12-month time points. As with VAS results, disability and quality-of-life scores measured through ODI and EQ-5D, respectively, improved at 3 months postintervention and were maintained at 12 months postintervention for both education groups. Significance was not seen, however, in
TABLE 2. Baseline patient characteristics in each education group

\begin{tabular}{|c|c|c|c|}
\hline Characteristic & $\begin{array}{c}\text { High School } \\
\text { or Less, } \\
n=27\end{array}$ & $\begin{array}{c}\text { College } \\
\text { Education, } \\
n=74\end{array}$ & $\begin{array}{c}p \\
\text { Value }\end{array}$ \\
\hline Age, yrs & $60.27 \pm 11.94$ & $61.96 \pm 13.67$ & 0.574 \\
\hline BMI & $28.97 \pm 5.70$ & $28.77 \pm 6.70$ & 0.893 \\
\hline \multicolumn{4}{|l|}{ Sex } \\
\hline Male & $17(62.96)$ & $47(63.51)$ & 1.000 \\
\hline Female & $10(37.04)$ & $27(36.49)$ & 1.000 \\
\hline \multicolumn{4}{|l|}{ Insurance payer } \\
\hline Medicare & $10(37.04)$ & $36(48.65)$ & 0.418 \\
\hline Medicaid & $0(0.00)$ & $0(0.00)$ & 1.000 \\
\hline Private & $13(48.15)$ & $33(44.59)$ & 0.925 \\
\hline VA/government & $3(11.11)$ & $5(6.76)$ & 0.727 \\
\hline Uninsured & $1(3.70)$ & $0(0.00)$ & 0.535 \\
\hline \multicolumn{4}{|l|}{ Smoker } \\
\hline $\begin{array}{l}\text { Current; every day or } \\
\text { almost daily }\end{array}$ & $7(25.93)$ & $12(16.22)$ & 0.409 \\
\hline $\begin{array}{l}\text { Current; some days or } \\
\text { occasional }\end{array}$ & $0(0.00)$ & $1(1.35)$ & 1.000 \\
\hline $\begin{array}{l}\text { Do not know if currently } \\
\text { smoking }\end{array}$ & $0(0.00)$ & $0(0.00)$ & 1.000 \\
\hline No & $20(74.07)$ & $61(82.43)$ & 0.506 \\
\hline \multicolumn{4}{|l|}{ Diabetes } \\
\hline $\begin{array}{l}\text { Non-insulin-dependent } \\
\quad \text { type } 2\end{array}$ & $3(11.11)$ & $8(10.81)$ & 1.000 \\
\hline Insulin-dependent type 2 & $3(11.11)$ & $2(2.70)$ & 0.234 \\
\hline Insulin-dependent type 1 & $0(0.00)$ & $0(0.00)$ & 1.000 \\
\hline No & $21(77.78)$ & $64(86.49)$ & 0.443 \\
\hline \multicolumn{4}{|l|}{ Depression disorder diagnosis } \\
\hline Yes & $3(11.11)$ & $14(18.92)$ & 0.545 \\
\hline No & $24(88.89)$ & $60(81.08)$ & 0.545 \\
\hline \multicolumn{4}{|l|}{ Ambulation type } \\
\hline Independent & $20(74.07)$ & $62(83.78)$ & 0.557 \\
\hline $\begin{array}{l}\text { Wheelchair bound (nonam- } \\
\text { bulatory) }\end{array}$ & $0(0.00)$ & $1(1.35)$ & 1.000 \\
\hline With an assist device & $5(18.52)$ & $8(10.81)$ & 0.439 \\
\hline \multicolumn{4}{|l|}{ Ethnicity } \\
\hline Asian & $0(0.00)$ & $2(2.70)$ & 1.000 \\
\hline Black or African American & $5(18.52)$ & $4(5.41)$ & 0.11 \\
\hline White & $22(81.48)$ & $67(90.54)$ & 0.365 \\
\hline Other & $0(0.00)$ & $1(1.35)$ & 1.000 \\
\hline \multicolumn{4}{|l|}{$\begin{array}{l}\text { ASA grade (per anesthesia op } \\
\text { report) }\end{array}$} \\
\hline 1 & $1(3.70)$ & $2(2.70)$ & 1.000 \\
\hline 2 & $5(18.52)$ & $21(28.38)$ & 0.462 \\
\hline 3 & $21(77.78)$ & $50(67.57)$ & 0.46 \\
\hline 4 & $0(0.00)$ & $1(1.35)$ & 1.000 \\
\hline
\end{tabular}


» CONTINUED FROM PAGE 62

TABLE 2. Baseline patient characteristics in each education group

\begin{tabular}{|c|c|c|c|}
\hline Characteristic & $\begin{array}{c}\text { High School } \\
\text { or Less, } \\
n=27\end{array}$ & $\begin{array}{c}\text { College } \\
\text { Education, } \\
n=74\end{array}$ & $\begin{array}{c}p \\
\text { Value }\end{array}$ \\
\hline \multicolumn{4}{|c|}{$\begin{array}{l}\text { Laminectomy or laminotomy } \\
\text { performed }\end{array}$} \\
\hline 1 (1 level) & $12(44.44)$ & $20(27.03)$ & 0.158 \\
\hline 2 (2 levels) & $9(33.33)$ & $34(45.95)$ & 0.365 \\
\hline 3 (3 levels) & $3(11.11)$ & $15(20.27)$ & 0.45 \\
\hline 4 (4 levels) & $3(11.11)$ & $3(4.05)$ & 0.384 \\
\hline \multicolumn{4}{|l|}{ Arthrodesis performed } \\
\hline 1 (1 level) & $2(7.41)$ & $3(4.05)$ & 0.809 \\
\hline 2 (2 levels) & $1(3.70)$ & $3(4.05)$ & 1.000 \\
\hline 3 (3 levels) & $0(0.00)$ & $0(0.00)$ & 1.000 \\
\hline 4 (4 levels) & $0(0.00)$ & $0(0.00)$ & 1.000 \\
\hline \multicolumn{4}{|l|}{ Duration of symptoms } \\
\hline$>3 \mathrm{mos}$ & $26(96.30)$ & $66(89.19)$ & 0.496 \\
\hline$<3 \mathrm{mos}$ & $1(3.70)$ & $7(9.46)$ & 0.630 \\
\hline Unknown & $0(0.00)$ & $1(1.35)$ & 1.000 \\
\hline \multicolumn{4}{|l|}{ Occupation description* } \\
\hline Heavy & $3(11.11)$ & $5(6.76)$ & 0.786 \\
\hline Medium & $1(3.70)$ & $6(8.11)$ & 0.712 \\
\hline Light & $3(11.11)$ & $8(10.81)$ & 1.000 \\
\hline Sedentary & $5(18.52)$ & $12(16.22)$ & 1.000 \\
\hline
\end{tabular}

ASA = American Society of Anesthesiologists; $V A=$ Veterans Affairs.

Values are expressed as the number of patients (\%) or as the mean \pm SD.

* Heavy $=$ stand up to 6 hours in 8-hour workday, lift up to $50 \mathrm{lbs}$ frequently, lift $>50 \mathrm{lbs}$ occasionally; medium = stand up to 6 hours in 8-hour workday, lift up to $25 \mathrm{lbs}$ frequently, lift $>50 \mathrm{lbs}$ occasionally; light = stand up to 6 hours in 8-hour workday, lift up to $10 \mathrm{lbs}$ frequently, lift > $20 \mathrm{lbs}$ occasionally; sedentary $=$ sit up to 6 hours in 8 -hour workday, lift light objects such as files and paperwork frequently, lift $>10 \mathrm{lbs}$ occasionally.

a comparison between 3- and 12-month assessments for either cohort.

\section{Multivariate Analysis: Multiple Regressions Baseline}

A multivariate analysis was performed whereby the education level was stratified into less than high school education, high school diploma or GED, 2-year college degree, or 4-year college degree, and/or postgraduate education. Sex, smoking status, diabetes, and reported depression were included as covariates.

At baseline, an education level less than high school had an association with increased back pain and a lower quality of life. In those with a high school education or GED, there was also an association with increased back pain and a decreased quality of life. There were no significant associations among patients with 2- or 4-year college degrees or postgraduate education levels and the 4 patient-reported outcomes of back pain, leg pain, disability as measured by the ODI, and quality of life as measured by EQ-5D. Among the covariates, smoking and insulin-dependent diabetes were strongly associated with patient disability. Non-insulin-dependent diabetes was significant for higher back and leg pain scores, as well as a decreased quality of life (Table 5).

\section{Three Months Postintervention}

Three-month multiple regression analysis showed no statistically significant association between education level and back pain, leg pain, disability, or quality of life. However, depression was associated with increased back pain and disability, with scores of 2.385 and 16.724 , respectively $(p<0.05)$. It was also associated with a decreased quality of life $(\mathrm{EQ}-5 \mathrm{D}=-0.223, \mathrm{p}<0.05)$.

\section{Twelve Months Postintervention}

Table 6 shows a multivariate analysis of outcomes at 12 months postintervention. The data show a significant association between postgraduate education and less back pain and less disability. Depression and type 2 insulindependent diabetes were associated with increased disability, and depression was also associated with increased back pain. There were no associations seen between the 4 outcomes in the less-educated cohorts (i.e., less than high school or high school/GED).

\section{Difference Between Baseline and 12 Months Postintervention}

Table 7 is a multivariate analysis of the difference in magnitude between baseline and 12 months postintervention among the 4 patient-reported outcomes. These data indicate a significant association between patients with a postgraduate education and reduced leg pain, less disability, and higher quality of life. On the contrary, those with depression showed less improvement in disability between baseline and 12 months postintervention. Once again, the less than high school and the high school/GED groups showed no statistically significant association between covariates and outcomes across the 4 parameters.

\section{Discussion}

In choosing to perform decompressive surgery for symptomatic lumbar spinal stenosis, the chief aims of an intervention are often pain reduction, improved function, and improved quality of life for the patient. Because these goals are primarily subjective evaluations best understood by the patients themselves, scoring systems such as the VAS, ODI, and the EQ-5D questionnaire are valuable in determining the success of surgery from the patient's perspective. ${ }^{3}$ However, numerous patient factors can contribute to the patient's ultimate perception and, therefore, interpretation of the success of care. This study was an attempt to identify a patient's education level as a probable determinant of patient-reported outcomes.

In this study, patients with less education reported greater back and leg pain VAS scores preoperatively than their more-educated counterparts. ${ }^{13}$ Despite this, both cohorts showed improvement in their functional outcomes at 3 and 12 months after decompression surgery for symptomatic lumbar spinal stenosis, irrespective of education level. Consequently, this study suggests that less education does not preclude benefit from decompression surgery for 
TABLE 3. Patient-reported outcomes at baseline and 3 months and 12 months postoperatively

\begin{tabular}{|c|c|c|c|c|c|}
\hline Outcome & $\begin{array}{l}\text { High School or Less, } \\
\qquad n=27\end{array}$ & $\begin{array}{l}\text { College Education, } \\
\qquad n=74\end{array}$ & $\begin{array}{c}\text { Mean } \\
\text { Difference }\end{array}$ & $95 \% \mathrm{Cl}$ & $\begin{array}{c}p \\
\text { Value }\end{array}$ \\
\hline \multicolumn{6}{|c|}{ Back pain on a scale of $0-10$ over the past 7 days } \\
\hline Baseline & $8.33(1.96)$ & $6.24(2.48)$ & 2.09 & 1.16 to 3.02 & $<0.001$ \\
\hline 3-mo & $2.65(3.04)$ & $2.13(2.08)$ & 0.52 & -0.84 to 1.89 & 0.393 \\
\hline 12-mo & $3.65(3.07)$ & $2.64(2.72)$ & 1.01 & -0.64 to 2.66 & 0.217 \\
\hline \multicolumn{6}{|c|}{ Leg pain on a scale of $0-10$ over the past 7 days } \\
\hline Baseline & $8.15(2.19)$ & $6.46(2.59)$ & 1.69 & 0.67 to 2.70 & $<0.001$ \\
\hline 3-mo & $2.23(3.00)$ & $2.56(2.86)$ & 0.33 & -1.14 to 1.80 & 0.66 \\
\hline 12-mo & $2.50(2.81)$ & $2.45(2.66)$ & 0.05 & -1.52 to 1.63 & 0.947 \\
\hline \multicolumn{6}{|l|}{ Total EQ-5D score } \\
\hline Baseline & $0.46(0.25)$ & $0.56(0.21)$ & 0.1 & -0.00 to 0.21 & $<0.001$ \\
\hline 3-mo & $0.72(0.26)$ & $0.79(0.20)$ & 0.07 & -0.04 to 0.20 & 0.167 \\
\hline 12-mo & $0.75(0.25)$ & $0.80(0.18)$ & 0.05 & -0.08 to 0.19 & 0.343 \\
\hline \multicolumn{6}{|l|}{ Total ODI sum score } \\
\hline Baseline & 49.04 (15.51) & $42.89(15.64)$ & 6.15 & -0.71 to 13.00 & 0.086 \\
\hline 3-mo & $25.30(23.44)$ & $18.47(16.87)$ & 6.83 & -3.73 to 17.40 & 0.158 \\
\hline 12-mo & $21.88(19.02)$ & $17.79(17.09)$ & 4.09 & -6.16 to 14.34 & 0.421 \\
\hline
\end{tabular}

Values are expressed as the mean (SD). Boldface type indicates statistical significance.

symptomatic lumbar spinal stenosis and should not alter expectations for improved outcomes.

The fact that patients without college education demonstrated increased baseline back and leg pain VAS scores may actually represent pain catastrophizing. Other studies have described this phenomenon as an exaggerated response to actual or expected pain, and it has been suggested to be inversely related to patient education level. ${ }^{9,12-14,23}$ Increased sensitivity to pain and pain catastrophizing negatively impact disability and back and/or leg pain VAS scores in lumbar spinal stenosis..$^{13-15}$ However, a study by $\mathrm{Kim}$ et al. demonstrated that increased baseline pain catastrophizing was not predictive of 12-month outcomes in patients undergoing surgery for spinal stenosis. ${ }^{15}$ They went on to show that although education level affected the back pain VAS score, the association lost significance when controlling for pain catastrophizing, implying a mediating role for this phenomenon. ${ }^{13}$ Our results support this conclusion.

\section{Minimum Clinically Important Difference}

Patient-reported outcome measures can be ambiguous in their clinical significance. To address this, the minimum clinically important difference (MCID) is a proposed threshold value that must be met to signify clinical signifi-
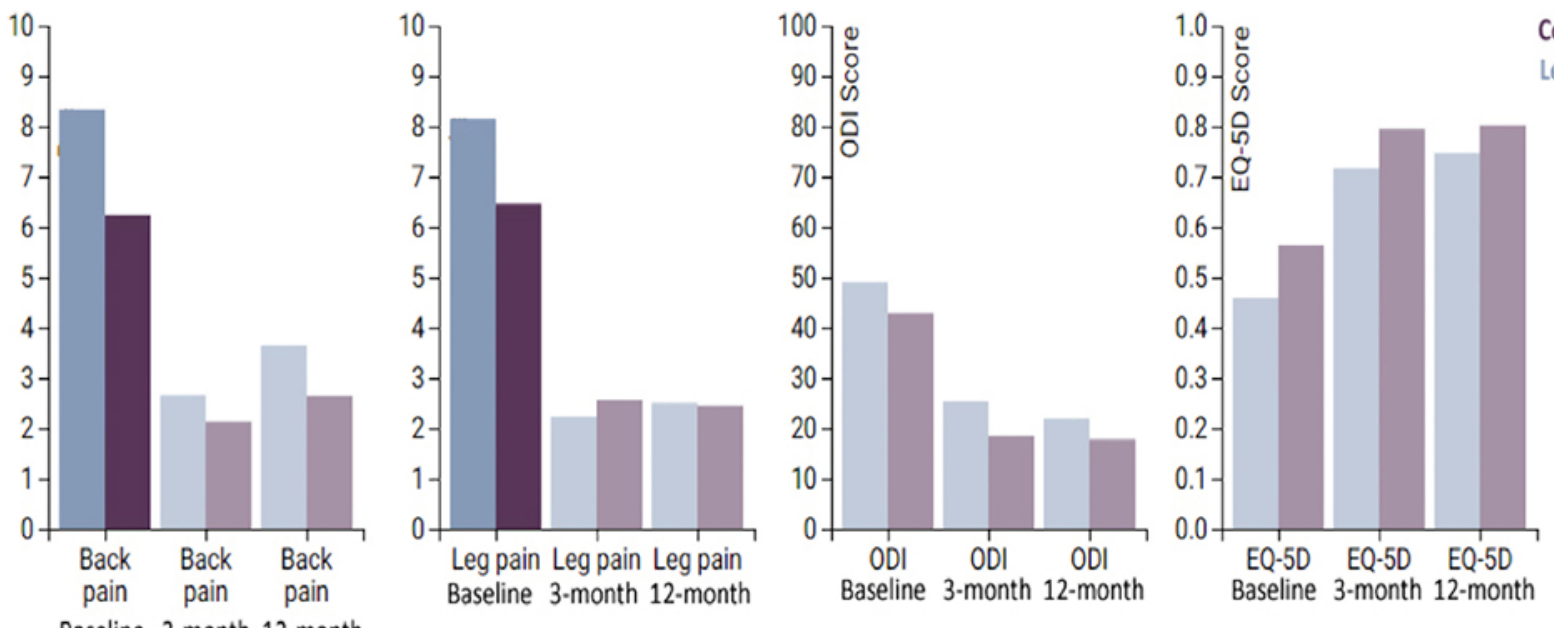

College Educated Less than College

Baseline 3-month 12-month

FIG. 1. Bar graphs showing comparisons of education level among patient-reported outcomes measured as back pain, leg pain, ODI score, and EQ-5D. Opaque (darker) bars indicate a statistically significant difference between the 2 cohorts at $p<0.05$.

Figure is available in color online only. 
TABLE 4. Patient-reported outcomes compared between time points

\begin{tabular}{lrrrr}
\hline \multicolumn{1}{c}{ Outcome } & High School or Less, $n=23$ & $p$ Value & College Education, $n=55$ & $p$ Value \\
\hline Back pain on a scale of 0-10 over the past 7 days & & & & \\
\hline Baseline vs 3-mo & $5.78(3.35)$ & $<0.001$ & $4.31(2.96)$ & $<0.001$ \\
\hline Baseline vs 12-mo & $4.29(3.41)$ & $<0.001$ & $3.81(3.40)$ & $<0.001$ \\
\hline 3-mo vs 12-mo & $-1.80(3.04)$ & $<0.001$ & $-0.38(2.69)$ & 0.405 \\
\hline Leg pain on a scale of 0-10 over the past 7 days & & & & \\
\hline Baseline vs 3-mo & $6.23(2.92)$ & $<0.001$ & $4.09(3.41)$ & $<0.001$ \\
\hline Baseline vs 12-mo & $5.38(3.31)$ & $<0.001$ & $4.30(3.37)$ & $<0.001$ \\
\hline 3-mo vs 12-mo & $-1.71(2.84)$ & $<0.001$ & $0.22(2.70)$ & 0.634 \\
\hline Total ODI sum score & & & & \\
\hline Baseline vs 3-mo & $26.09(15.28)$ & $<0.001$ & $24.84(17.22)$ & $<0.001$ \\
\hline Baseline vs 12-mo & $23.41(13.28)$ & $<0.001$ & $24.71(17.70)$ & $<0.001$ \\
\hline 3-mo vs 12-mo & $-4.27(17.98)$ & 0.389 & $0.32(13.72)$ & 0.889 \\
\hline Total EQ-5D score & & & & $<$ \\
\hline Baseline vs 3-mo & $-0.30(0.20)$ & $<0.001$ & $-0.24(0.27)$ & $<0.001$ \\
\hline Baseline vs 12-mo & $-0.21(0.26)$ & $<0.001$ & $-0.25(0.22)$ & $<0.001$ \\
\hline 3-mo vs 12-mo & $0.06(0.25)$ & 0.355 & $0.02(0.13)$ & 0.496 \\
\hline
\end{tabular}

Values are expressed as the mean difference (SD). Boldface type indicates statistical significance.

cance. ${ }^{5-7,11,15,19-21,25}$ Copay et al..$^{6,7}$ calculated MCID values in lumbar spine surgery across a variety of pathologies: spinal stenosis, disc herniation, spondylolisthesis, and mechanical instability requiring fusion. In their conclusion, they reported MCID values for lumbar spine surgery to be observed differences of 12.8 for ODI and 1.2 and 1.6 for back pain and leg pain VAS scores, respectively. Considering the above definitions for MCID values, patients in this study reached MCID thresholds for ODI and back and leg pain VAS scores in both cohorts by 3 months postintervention and maintained this improvement at 12 months postintervention (Table 4).

TABLE 5. Baseline patient-reported outcomes: multiple regression

\begin{tabular}{|c|c|c|c|c|}
\hline \multirow[b]{2}{*}{ Variable } & \multicolumn{4}{|c|}{ Parameter Estimate (SE) } \\
\hline & Back Pain & Leg Pain & ODI Score & $E Q-5 D$ \\
\hline Male sex & $0.085(0.518)$ & $-0.349(0.549)$ & $-0.597(3.252)$ & $-0.033(0.045)$ \\
\hline \multicolumn{5}{|l|}{ Smoker } \\
\hline Every day & $0.361(0.652)$ & $0.204(0.690)$ & $11.515(4.086)^{* * *}$ & $-0.081(0.057)$ \\
\hline Some days or occasional & $-0.461(2.576)$ & $1.296(2.729)$ & $-17.501(16.156)$ & $-0.041(0.226)$ \\
\hline \multicolumn{5}{|l|}{ Diabetes } \\
\hline Insulin-dependent type 2 & $1.821(1.105)$ & $1.968(1.170)$ & $14.365(6.927)^{\star *}$ & $-0.342(0.097)^{\star * *}$ \\
\hline Non-insulin-dependent type 2 & $1.739(0.810)^{* *}$ & $1.861(0.858)^{\star *}$ & $9.993(5.080)$ & $-0.146(0.071)^{\star *}$ \\
\hline Depression disorder & $1.353(0.693)$ & $0.972(0.734)$ & $2.313(4.348)$ & $-0.175(0.061)^{* * *}$ \\
\hline \multicolumn{5}{|l|}{ Level of education } \\
\hline Less than high school & $3.211(1.446)^{* *}$ & $1.417(1.532)$ & $17.768(9.068)^{*}$ & $-0.254(0.127)^{* *}$ \\
\hline High school diploma or GED & $2.155(0.678)^{\star * *}$ & $1.972(0.718)^{* * *}$ & $2.582(4.252)$ & $-0.100(0.059)$ \\
\hline 2-yr college degree & $0.407(0.747)$ & $0.588(0.791)$ & $4.845(4.685)$ & $-0.037(0.066)$ \\
\hline Postgraduate & $0.481(0.630)$ & $0.492(0.668)$ & $-1.516(3.954)$ & $-0.071(0.055)$ \\
\hline Intercept & $5.368(0.569)^{* \star *}$ & $5.871(0.603)^{* * *}$ & $39.195(3.569)^{* \star *}$ & $0.692(0.050)^{* * *}$ \\
\hline Observations & 101 & 101 & 101 & 101 \\
\hline $\mathrm{R}^{2}$ & 0.243 & 0.196 & 0.242 & 0.289 \\
\hline Adjusted $\mathrm{R}^{2}$ & 0.159 & 0.106 & 0.157 & 0.210 \\
\hline Residual SE (df = 90) & 2.330 & 2.469 & 14.616 & 0.204 \\
\hline F statistic $(\mathrm{df}=10 ; 90)$ & $2.896^{\star * *}$ & $2.190^{* *}$ & $2.867^{* * *}$ & $3.653^{* * *}$ \\
\hline
\end{tabular}

Boldface type indicates statistical significance: ${ }^{*} p<0.1 ;{ }^{* *} p<0.05 ;{ }^{* * *} p<0.01$. 
TABLE 6. Twelve months postintervention for patient-reported outcomes: multiple regression

\begin{tabular}{|c|c|c|c|c|}
\hline \multirow[b]{2}{*}{ Variable } & \multicolumn{4}{|c|}{ Parameter Estimate (SE) } \\
\hline & Back Pain & Leg Pain & ODI Score & $E Q-5 D$ \\
\hline Male sex & $1.452(0.865)$ & $0.586(0.903)$ & $6.450(5.144)$ & $-0.052(0.065)$ \\
\hline Smoke every day & $-1.447(0.996)$ & $-0.640(1.038)$ & $1.208(5.925)$ & $0.015(0.075)$ \\
\hline \multicolumn{5}{|l|}{ Diabetes } \\
\hline Insulin-dependent type 2 & $1.994(1.689)$ & $1.526(1.751)$ & $25.840(10.033)^{\star *}$ & $-0.213(0.126)$ \\
\hline Non-insulin-dependent type 2 & $0.992(1.243)$ & $1.040(1.286)$ & $2.638(7.374)$ & $-0.104(0.093)$ \\
\hline Known depression disorder & $3.050(1.138)^{* * *}$ & $1.391(1.178)$ & $14.236(6.764)^{* *}$ & $-0.071(0.085)$ \\
\hline \multicolumn{5}{|l|}{ Level of education } \\
\hline Less than high school & $-1.186(2.936)$ & $-1.355(3.037)$ & $-9.105(17.463)$ & $0.071(0.220)$ \\
\hline High school diploma or GED & $0.566(0.947)$ & $0.124(1.002)$ & $-1.998(5.636)$ & $-0.014(0.071)$ \\
\hline 2-yr college degree & $-1.343(1.141)$ & $0.576(1.180)$ & $-4.591(6.785)$ & $0.066(0.085)$ \\
\hline Postgraduate & $-1.970(0.930)^{* *}$ & $-0.930(0.962)$ & $-16.892(5.456)^{* * *}$ & $0.119(0.070)$ \\
\hline Intercept & $2.137(0.889)^{* *}$ & $1.964(0.922)^{\star \star}$ & $16.870(5.289)^{\star \star *}$ & $0.810(0.067)^{* * *}$ \\
\hline Observations & 64 & 63 & 65 & 64 \\
\hline $\mathrm{R}^{2}$ & 0.216 & 0.069 & 0.280 & 0.122 \\
\hline Adjusted $\mathrm{R}^{2}$ & 0.085 & -0.089 & 0.162 & -0.025 \\
\hline Residual SE & $2.746(\mathrm{df}=54)$ & $2.841(\mathrm{df}=53)$ & $16.337(\mathrm{df}=55)$ & $0.205(\mathrm{df}=54)$ \\
\hline F statistic & $1.653(d f=9 ; 54)$ & $0.439(\mathrm{df}=9 ; 53)$ & $2.374(\mathrm{df}=9 ; 55)^{\star *}$ & $0.830(\mathrm{df}=9 ; 54)$ \\
\hline
\end{tabular}

Boldface type indicates statistical significance: ${ }^{*} p<0.1 ;{ }^{* *} p<0.05 ;{ }^{* *} p<0.01$.

In addition to the work by Copay et al., other studies have also attempted to define MCIDs. In patients with nonspecific low-back pain, van der Roer et al. ${ }^{25}$ calculated the MCID for EQ (EuroQol) as a range from 0.07 to 0.58, whereas Parker et al. ${ }^{20}$ reported an MCID of 0.39 for EQ-
5D, 2.2 for back pain VAS, 5.0 for leg pain VAS, and 8.2 for ODI in patients with recurrent stenosis. Pearson et al. ${ }^{21}$ identified an ODI difference of 11 as sufficient for MCID in their subgroup analysis of lumbar spinal stenosis from the SPORT, which is more consistent with other reports

TABLE 7. Difference in magnitude between baseline and 12 months postintervention for patient-reported outcomes: multiple regression

\begin{tabular}{|c|c|c|c|c|}
\hline \multirow[b]{2}{*}{ Variable } & \multicolumn{4}{|c|}{ Parameter Estimate (SE) } \\
\hline & Back Pain & Leg Pain & ODI Score & $E Q-5 D$ \\
\hline Male sex & $-0.878(1.082)$ & $-1.082(1.088)$ & $-7.407(4.907)$ & $0.036(0.072)$ \\
\hline Smoke every day & $2.076(1.246)$ & $0.635(1.250)$ & $7.260(5.652)$ & $0.061(0.083)$ \\
\hline \multicolumn{5}{|l|}{ Diabetes } \\
\hline Insulin-dependent type 2 & $-0.462(2.112)$ & $0.013(2.109)$ & $-2.263(9.571)$ & $0.151(0.141)$ \\
\hline Non-insulin-dependent type 2 & $0.229(1.555)$ & $1.367(1.548)$ & $6.602(7.034)$ & $0.010(0.103)$ \\
\hline Depression disorder & $-1.761(1.424)$ & $0.456(1.419)$ & $-15.771(6.452)^{* *}$ & $0.126(0.095)$ \\
\hline \multicolumn{5}{|l|}{ Level of education } \\
\hline Less than high school & $3.605(3.673)$ & $3.899(3.658)$ & $26.192(16.659)$ & $0.135(0.244)$ \\
\hline High school diploma or GED & $1.248(1.185)$ & $1.913(1.207)$ & $2.700(5.376)$ & $0.049(0.079)$ \\
\hline 2-yr college degree & $2.056(1.427)$ & $1.004(1.421)$ & $5.699(6.473)$ & $0.069(0.095)$ \\
\hline Postgraduate & $2.248(1.163)$ & $2.357(1.159)^{\star \star}$ & $15.874(5.204)^{\star * *}$ & $0.201(0.077)^{\star *}$ \\
\hline Intercept & $3.156(1.112)^{\star \star *}$ & $3.644(1.110)^{* * *}$ & $23.579(5.046)^{\star * *}$ & $0.099(0.074)$ \\
\hline Observations & 64 & 63 & 65 & 64 \\
\hline $\mathrm{R}^{2}$ & 0.143 & 0.143 & 0.260 & 0.186 \\
\hline Adjusted $\mathrm{R}^{2}$ & 0.0004 & -0.003 & 0.139 & 0.050 \\
\hline Residual SE & $3.435(\mathrm{df}=54)$ & $3.421(\mathrm{df}=53)$ & $15.585(\mathrm{df}=55)$ & $0.229(\mathrm{df}=54)$ \\
\hline F statistic & $1.003(d f=9 ; 54)$ & $0.979(\mathrm{df}=9 ; 53)$ & $2.148(d f=9 ; 55)^{\star \star}$ & $1.370(\mathrm{df}=9 ; 54)$ \\
\hline
\end{tabular}

Boldface type indicates statistical significance: ${ }^{*} p<0.1 ;{ }^{* *} p<0.05 ;{ }^{* * *} p<0.01$. 
for ODI ${ }^{7,13}$ However, an MCID as high as 14.9 for ODI has also been reported. ${ }^{5}$

\section{Limitations of the Study}

Our study is limited by our small sample size and the fact that the data are from a single institution's prospective data registry in the southeastern United States. Whereas its predecessors, such as the SPORT, were multicenter, prospective studies, this paper is bound by the inherent restrictions of a single-center, retrospectively analyzed study of prospectively collected patient data. ${ }^{21}$ It is possible that geographical differences in education patterns and/or other regional differences may have influenced results, and it is therefore uncertain whether the findings of this study can be generalized to the entirety of the target population. Also, data on opioid use and types of pain control instituted among the different cohorts are not collected; these missing data could help elucidate the underlying problems with pain catastrophizing and its inferred association with less-educated patients. As a final potential confounder due to regionality, it is possible that there is selection bias in this study as a result of the clinical practices of the participating surgeons.

Another potential limitation is completeness of data across time points and insufficient power to detect subtle differences among the cohorts. For example, the univariate results for quality of life among the patients with no college education demonstrated a p value $<0.05$, but a confidence interval that crossed zero. In future studies with a larger sample size, this may instead reach statistical significance and may be addressed with future automated data extraction and abstraction. Also, minimally invasive and open surgical approaches are not specifically documented or separated in our database, which could offer significant insight. In the same way, the degree of preoperative lumbar spinal stenosis could be a potential contributor to postoperative patient-reported outcomes and could not be adequately addressed due to the limitations of the database.

Finally, our results do not meet the MCID values for EQ-5D in all patients and for VAS leg pain in patients with a college education compared to those proposed by Parker et al. ${ }^{19,20}$ This is of unclear significance because there are currently a variety of reported methods used to calculate MCID in the literature, leading to a wide range of values and a lack of standardization.

\section{Conclusions}

Regardless of patient education level, both cohorts showed improvement in their functional outcomes at 3 months and 12 months after decompression surgery for symptomatic lumbar spinal stenosis. Patient education level may therefore not represent a significant prognostic factor for improvement after decompression surgery for symptomatic lumbar spinal stenosis.

\section{References}

1. Aleem IS, Rampersaud YR: Elderly patients have similar outcomes compared to younger patients after minimally invasive surgery for spinal stenosis. Clin Orthop Relat Res 472:1824-1830, 2014
2. Asher AL, McCormick PC, Selden NR, Ghogawala Z, McGirt MJ: The National Neurosurgery Quality and Outcomes Database and NeuroPoint Alliance: rationale, development, and implementation. Neurosurg Focus 34(1):E2, 2013

3. Asher AL, Speroff T, Dittus RS, Parker SL, Davies JM, Selden N, et al: The National Neurosurgery Quality and Outcomes Database (N2QOD): a collaborative North American outcomes registry to advance value-based spine care. Spine (Phila Pa 1976) 39 (22 Suppl 1):S106-S116, 2014

4. Black N: Patient reported outcome measures could help transform healthcare. BMJ 346:f167, 2013

5. Chotai S, Sivaganesan A, Parker SL, McGirt MJ, Devin CJ: Patient-specific factors associated with dissatisfaction after elective surgery for degenerative spine diseases. Neurosurgery 77:157-163, 2015

6. Copay AG, Glassman SD, Subach BR, Berven S, Schuler TC, Carreon LY: Minimum clinically important difference in lumbar spine surgery patients: a choice of methods using the Oswestry Disability Index, Medical Outcomes Study questionnaire Short Form 36, and pain scales. Spine J 8:968-974, 2008

7. Copay AG, Subach BR, Glassman SD, Polly DW Jr, Schuler TC: Understanding the minimum clinically important difference: a review of concepts and methods. Spine J 7:541-546, 2007

8. den Boer JJ, Oostendorp RAB, Beems T, Munneke M, Oerlemans M, Evers AWM: A systematic review of bio-psychosocial risk factors for an unfavourable outcome after lumbar disc surgery. Eur Spine J 15:527-536, 2006

9. Edwards RR, Goble L, Kwan A, Kudel I, McGuire L, Heinberg L, et al: Catastrophizing, pain, and social adjustment in scleroderma: relationships with educational level. Clin J Pain 22:639-646, 2006

10. Feldman CH, Dong Y, Katz JN, Donnell-Fink LA, Losina E: Association between socioeconomic status and pain, function and pain catastrophizing at presentation for total knee arthroplasty. BMC Musculoskelet Disord 16:18, 2015

11. Gum JL, Glassman SD, Carreon LY: Clinically important deterioration in patients undergoing lumbar spine surgery: a choice of evaluation methods using the Oswestry Disability Index, 36-Item Short Form Health Survey, and pain scales: clinical article. J Neurosurg Spine 19:564-568, 2013

12. Hannan MT, Anderson JJ, Pincus T, Felson DT: Educational attainment and osteoarthritis: differential associations with radiographic changes and symptom reporting. J Clin Epidemiol 45:139-147, 1992

13. Kim HJ, Kim SC, Kang KT, Chang BS, Lee CK, Yeom JS: Influence of educational attainment on pain intensity and disability in patients with lumbar spinal stenosis: mediation effect of pain catastrophizing. Spine (Phila Pa 1976) 39:E637-E644, 2014

14. Kim HJ, Lee JI, Kang KT, Chang BS, Lee CK, Ruscheweyh $\mathrm{R}$, et al: Influence of pain sensitivity on surgical outcomes after lumbar spine surgery in patients with lumbar spinal stenosis. Spine (Phila Pa 1976) 40:193-200, 2015

15. Kim HJ, Park JW, Chang BS, Lee CK, Yeom JS: The influence of catastrophising on treatment outcomes after surgery for lumbar spinal stenosis. Bone Joint J 97-B:1546-1554, 2015

16. Koerner JD, Glaser J, Radcliff K: Which variables are associated with patient-reported outcomes after discectomy? Review of SPORT disc herniation studies. Clin Orthop Relat Res 473:2000-2006, 2015

17. McGirt MJ, Speroff T, Dittus RS, Harrell FE Jr, Asher AL: The National Neurosurgery Quality and Outcomes Database (N2QOD): general overview and pilot-year project description. Neurosurg Focus 34(1):E6, 2013

18. Olson PR, Lurie JD, Frymoyer J, Walsh T, Zhao W, Morgan TS, et al: Lumbar disc herniation in the Spine Patient Out- 
comes Research Trial: does educational attainment impact outcome? Spine (Phila Pa 1976) 36:2324-2332, 2011

19. Parker SL, Adogwa O, Paul AR, Anderson WN, Aaronson $\mathrm{O}$, Cheng JS, et al: Utility of minimum clinically important difference in assessing pain, disability, and health state after transforaminal lumbar interbody fusion for degenerative lumbar spondylolisthesis. J Neurosurg Spine 14:598-604, 2011

20. Parker SL, Mendenhall SK, Shau DN, Adogwa O, Anderson WN, Devin CJ, et al: Minimum clinically important difference in pain, disability, and quality of life after neural decompression and fusion for same-level recurrent lumbar stenosis: understanding clinical versus statistical significance. J Neurosurg Spine 16:471-478, 2012

21. Pearson A, Lurie J, Tosteson T, Zhao W, Abdu W, Weinstein JN: Who should have surgery for spinal stenosis? Treatment effect predictors in SPORT. Spine (Phila Pa 1976) 37:17911802, 2012

22. Radcliff K, Freedman M, Hilibrand A, Isaac R, Lurie JD, Zhao W, et al: Does opioid pain medication use affect the outcome of patients with lumbar disc herniation? Spine (Phila Pa 1976) 38:E849-E860, 2013

23. Roth RS, Geisser ME: Educational achievement and chronic pain disability: mediating role of pain-related cognitions. Clin J Pain 18:286-296, 2002

24. Sedighi M, Haghnegahdar A: Lumbar disk herniation surgery: outcome and predictors. Global Spine J 4:233-244, 2014

25. van der Roer N, Ostelo RWJG, Bekkering GE, van Tulder MW, de Vet HCW: Minimal clinically important change for pain intensity, functional status, and general health status in patients with nonspecific low back pain. Spine (Phila Pa 1976) 31:578-582, 2006

26. von Elm E, Altman DG, Egger M, Pocock SJ, Gøtzsche PC, Vandenbroucke JP: The Strengthening the Reporting of Observational Studies in Epidemiology (STROBE) statement: guidelines for reporting observational studies. Lancet 370:1453-1457, 2007

27. Weinstein JN, Tosteson TD, Lurie JD, Tosteson ANA, Blood E, Hanscom B, et al: Surgical versus nonsurgical therapy for lumbar spinal stenosis. N Engl J Med 358:794-810, 2008

28. Winkleby MA, Jatulis DE, Frank E, Fortmann SP: Socioeconomic status and health: how education, income, and occupation contribute to risk factors for cardiovascular disease. Am J Public Health 82:816-820, 1992

\section{Disclosures}

Dr. Erwood was the North Family Clinical Scholar in the Department of Neurosurgery at the University of Alabama at Birmingham during the study period.

\section{Author Contributions}

Conception and design: Elsayed. Acquisition of data: Elsayed. Analysis and interpretation of data: Elsayed, Szerlip. Drafting the article: Erwood, Dupépé. Critically revising the article: Erwood, Elsayed, Walters, Hadley. Reviewed submitted version of manuscript: Erwood, Dupépé, Davis, McClugage, Walters, Hadley. Approved the final version of the manuscript on behalf of all authors: Erwood. Statistical analysis: Elsayed. Administrative/ technical/material support: Davis, McClugage, Walters, Hadley. Study supervision: Walters, Hadley.

\section{Correspondence}

Matthew S. Erwood: University of Alabama at Birmingham, AL. merwood@uabmc.edu. 